\title{
INFLUENCE OF THE PARAMETERS OF MODELS USED TO CALCULATE SOIL EROSION BASED ON ${ }^{137}$ CS TRACER
}

\author{
GRZEGORZ J. PORĘBA and ANDRZEJ BLUSZCZ \\ Department of Radioisotopes, Institute of Physics, Silesian University of Technology, \\ Krzywoustego 2, 44-100 Gliwice, Poland
}

Received 8 February 2008

Accepted 11 December 2008

\begin{abstract}
Soil erosion is a serious problem especially on arable land in the loess areas of southern Poland. Reliable data of soil erosion are important to propose a proper method of soil conservation. Measurements of ${ }^{137} \mathrm{Cs}$ inventory allow obtaining both long-term mean value of soil erosion and spatial pattern of soil erosion. To obtain quantitative results of soil erosion from ${ }^{137} \mathrm{Cs}$ measurements one of the mathematical models must be used. Currently, there are many such models in circulation and the results of calculations of soil erosion depend not only on the particular model but also on values assumed for parameters of this model.

This paper describes some problems related to calculating soil erosion and deposition based on ${ }^{137} \mathrm{Cs}$ data, namely, the influence of additional parameters on calculated soil erosion is considered. In particular, we have considered the influence of values assumed for plough depth, $\gamma$ factor, particle size correction factor, soil density and the contribution of the post-Chernobyl deposition to the total caesium deposition on the calculated soil erosion values. The calculations of soil erosion have been done for four, most commonly used models, using real caesium inventory data collected by the authors. The influence of errors of model parameters on the results of soil erosion rate estimates is about $1 \%$, or less for $1 \%$ relative error in the parameter.
\end{abstract}

Keywords: ${ }^{137} \mathrm{Cs}$, soil erosion, mathematical models, proportional model, mass balance model, simplified mass balance model, refined mass balance model.

\section{INTRODUCTION}

It is widely known that soil erosion poses a serious problem in many environments. Accelerated soil erosion on agricultural fields, especially in loess areas, is currently an important issue and there is only limited information about soil erosion rates. It is mainly due to that the fact that the traditional methods of soil erosion estimation are time consuming and that results obtained for experimental plots are hardly comparable with one another (Toy et al., 2002). Use of ${ }^{137} \mathrm{Cs}$ for estimating soil erosion helps overcoming some of the limitations of traditional methods (Ritchie and McHenry, 1990) and makes it a valuable alternative. The spatial distribution of soil loss and its magnitude can be obtained by the ${ }^{137} \mathrm{Cs}$ method. The first attempts to use ${ }^{137} \mathrm{Cs}$ to estimate soil erosion were undertaken in the 1960-ties (Yamagata et al., 1963; Rogowski and Tamura, 1965) and since then

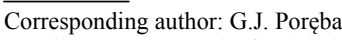
e-mail: Grzegorz.Poreba@polsl.pl

ISSN 1897-1695 (online), 1733-8387 (print) @ 2008 GADAM Centre, Institute of Physics, Silesian University of Technology.

All rights reserved.
${ }^{137} \mathrm{Cs}$ was used in soil erosion and deposition studies.

${ }^{137} \mathrm{Cs}$ is a fission product and a gamma emitter with energy of $661.6 \mathrm{keV}$ and half-life of 30.02 years. After deposition on the ground surface, ${ }^{137} \mathrm{Cs}$ becomes rapidly and strongly adsorbed on soil particles (Sawhney, 1972; Schultz et al., 1960; Schultz, 1965; Tamura, 1964). These properties make the ${ }^{137} \mathrm{Cs}$ isotope a valuable tracer of soil erosion in the medium term. For the last 40 years, the fallout ${ }^{137} \mathrm{Cs}$ has been widely used as environmental tracer to study soil erosion (Ritchie and McHenry, 1990; Zapata, 2003). The simple comparison of the ${ }^{137} \mathrm{Cs}$ inventory for the study area with the reference value of ${ }^{137} \mathrm{Cs}$ inventory for a non-eroded and non-deposited site allows recognition of erosion and depositional areas. But a quantitative assessment of soil erosion and deposition needs a mathematical model of the erosion process. There are many formulae existing that may be used to convert ${ }^{137} \mathrm{Cs}$ inventory measurement results into numerical estimates of soil erosion and/or deposition. In a nutshell, all of them may be divided into two main categories: empirical relationships and theoretical models. The empirical equations 
were established on a base of simultaneous measurements of ${ }^{137} \mathrm{Cs}$ and soil losses from erosion test plots (Menzel, 1960; Rogowski and Tamura, 1970; Ritchie et al., 1974). Usually the relationship between soil loss and ${ }^{137} \mathrm{Cs}$ loss is exponential. More reliable results of soil erosion estimation could be obtained from theoretical models, especially from Mass Balance Models (Walling and Quine, 1990; Walling and He, 1999). Unfortunately, using mathematical models requires additional parameters whose values, if not carefully chosen, can severely bias the results of soil erosion calculations.

Below, we compare values of soil erosion obtained in different models for caesium inventory data measured on a cultivated field on loess soil in Ujazd, southern Poland (Poręba, 2006; Poręba and Bluszcz, 2007). The models applied were the most commonly used ones, namely the Proportional Model (PM), Mass Balance Model (MBM), Refined Mass Balance Model (RMBM) and Simplified Mass Balance Model (SMBM). We also analyse sensitivity of the models to several additional parameters. In particular, we discuss the influence of soil density $(B)$, plough depth $(d)$, proportion of freshly deposited ${ }^{137} \mathrm{Cs}$ removed before the first ploughing $(\gamma)$, particle size corrector factor $(P)$, relaxation mass depth $(H)$ of the initial ${ }^{137} \mathrm{Cs}$ distribution in the soil profile and the influence of post-Chernobyl contribution to the total caesium deposition on modelled soil erosion values.

\section{CULTIVATED SOIL EROSION MODELS SE- LECTED FOR ANALYSES}

As mentioned above the four models selected for detail analyses were: PM, SMBM, MBM and RMBM.

The proportional models were established and used by many authors (for example, de Jong et al., 1983; Kachanowski, 1987). These model have been summarised by Walling and Quine in 1990. These models are based on the assumption that all deposited ${ }^{137} \mathrm{Cs}$ is completely mixed within the plough layer and thus the erosional soil loss is directly proportional to the reduction of caesium inventory in the soil profile. The model equation can be written as follows (Walling and Quine, 1990):

$$
R=\frac{B d X}{100 T}
$$

where: $X=\frac{A_{r e f}-A}{A_{r e f}} 100$ and

$R$ - mean soil erosion rate $\left(\mathrm{kg} \mathrm{m}^{-2} \mathrm{yr}^{-1}\right), B$ - bulk density of the soil $\left(\mathrm{kg} \mathrm{m}^{-3}\right), d$ - depth of plough layer $(\mathrm{m})$, $X$ - percentage reduction of ${ }^{137} \mathrm{Cs}$ inventory, $A_{\text {ref }}$ - local ${ }^{137} \mathrm{Cs}$ reference inventory $\left(\mathrm{Bq} \mathrm{m}^{-2}\right), \mathrm{A}-{ }^{137} \mathrm{Cs}$ inventory at the sampling point $\left(\mathrm{Bq} \mathrm{m^{-2 }}\right), T$ - time elapsed since beginning of ${ }^{137} \mathrm{Cs}$ accumulation (yr).

PM model requires apart from caesium inventory data only the bulk density of the soil and the depth of ploughing. The model is very easy to use but has several limitations. First, the model relies on the assumption that caesium is uniformly distributed within the plough layer. This results in caesium depletion being directly proportional to soil loss. It should be noted, that immediately after deposition, the surface contains more caesium than lower soil layers. It means that calculated soil loss may be overestimated (Walling and Quine, 1990). Second, due to selective removal of fine soil particles which adsorb ${ }^{137} \mathrm{Cs}$ more readily than the coarse grains, soil erosion may be again overestimated. To solve this problem the particle size correction factor $P$ should be incorporated into Eq. 2.1 (Walling and He, 2001). The proportional model does not take into account the fact that the presence of erosion leads to dilution of the caesium concentration in the cultivated soil in subsequent years of ploughing. The fact limits the use of PM to low erosion rates.

To overcome the limitations of PM models, the mass balance model was proposed (Walling and Quine, 1990; Walling and He, 1999; Kachanowski and de Yong, 1984). The mass balance model is described by the following equation:

$$
\frac{d A(t)}{d t}=I(t)-\left(\lambda+\frac{R}{d_{m}}\right) A(t)
$$

where:

$A(t)$ - cumulative ${ }^{137} \mathrm{Cs}$ activity per unit area $\left(\mathrm{Bq} \mathrm{m}^{-2}\right)$ at time $t, R$ - soil erosion rate $\left(\mathrm{kg} \mathrm{m}^{-2} \mathrm{yr}^{-1}\right), d_{m}$ - the average plough mass depth $\left(\mathrm{kg} \mathrm{m}^{-2} ; d_{m}=d \cdot B\right), \lambda$ - the radioactive decay constant for ${ }^{137} \mathrm{Cs}\left(\mathrm{yr}^{-1}\right), I(t)-$ annual ${ }^{137} \mathrm{Cs}$ deposition flux $\left(\mathrm{Bq} \mathrm{m}^{-2} \mathrm{yr}^{-1}\right)$.

The model takes into account the actual atmospheric deposition of ${ }^{137} \mathrm{Cs}$ as well as the dilution of ${ }^{137} \mathrm{Cs}$ by tillage. The authors concluded that this model is probably limited to sites where soil erosion is between 0.5 and $10 \mathrm{~kg} \mathrm{~m}^{-2} \mathrm{yr}^{-1}$. They also suggested that outside this range the relative errors are higher (Kachanowski and de Jong, 1984). The main reasons of incorrect estimation of soil erosion by MBM model are selectivity of soil erosion processes on the grain size distribution and removal of freshly deposited caesium with the soil uppermost layer before it is mixed into the plough layer.

To overcome problems related to selective sorption and erosion, and to removal of freshly deposited ${ }^{137} \mathrm{Cs}$, the mass balance model was improved by Walling and $\mathrm{He}$ (1999) to the form:

$$
\frac{d A(t)}{d t}=(1-\Gamma) I(t)-\left(\lambda+P \frac{R}{d_{m}}\right) A(t)
$$

where:

$\Gamma$ - fraction of freshly deposited ${ }^{137} \mathrm{Cs}$ removed by erosion before mixing into the plough layer, $P$ - particle size correction factor.

To establish the $P$ value for the study area, information on grain size distribution in soil and in eroded material is required. Usually the mobilized sediment moved by runoff is enriched in fine particles when compared to the original soil, and thus the parameter $P$ is not smaller than unity (Walling and He, 1999; He and Walling, 1996).

According to He and Walling (1997), if an initial distribution of ${ }^{137} \mathrm{Cs}$ can be assumed exponential, then $\Gamma$ may be expressed as: 


$$
\Gamma=P \gamma\left(1-e^{-R / H}\right)
$$

where:

$\gamma$ - proportion of annual ${ }^{137} \mathrm{Cs}$ input susceptible to removal by erosion depending on local agricultural and rainfall conditions; $H$ - the relaxation mass depth of the initial exponential distribution of ${ }^{137} \mathrm{Cs}$ in the soil profile $\left(\mathrm{kg} \cdot \mathrm{m}^{-2}\right) . H$ parameter can be experimentally assessed for particular location, whereas the value of $\gamma$ factor depends on the timing of cultivation operations and the rainfall time distribution (Walling and He, 1999).

This refined mass balance model is more realistic compared to the original mass balance model and to the simplified mass balance model presented below. RMBM model introduces three additional parameters: $H, \gamma$ and $P$.

The fourth model chosen for this study is a simplified mass balance model which was published by Zhang et al. in 1990 . The authors assumed that the total ${ }^{137} \mathrm{Cs}$ fallout occurred in 1963, rather than in the period from 1954 to 1976. Thus, the mean annual soil loss rate is expressed as follows:

$Y=\frac{d B}{P}\left[1-\left(1-\frac{X}{100}\right)^{1 /(t-1963)}\right]$

where:

$Y$ is the mean annual soil loss $\left(\mathrm{kg} \mathrm{m}^{-2}\right), t$ is the calendar year when $X$ was measured and other parameters are defined as in PM and RMBM models.

To account for the effects of selective removal of fine particles, the particle size correction factor $P$ may be used. Because of the assumed caesium deposition pattern, SMBM model is applicable to calendar years distant from 1963 and to areas with no post-Chernobyl caesium deposited.

\section{DATA USED IN CALCULATIONS}

The selected models were aplied to agricultural loess areas near Ujazd in southern Poland, used as a farmlad for more than 60 yeras. The detailed studies of ${ }^{137} \mathrm{Cs}$ deposition as well as physical and chemical properties of soil were a subject of a previous work presented by the current authors (Poręba and Bluszcz, 2007). The average altitude is about $220 \mathrm{~m}$ above see level and the inclination of slopes is in the range between $4^{\circ}$ and $10^{\circ}$. The average annual rainfall in this region is $675 \mathrm{~mm}$, with a minimum of $277 \mathrm{~mm}$ in 1953 and maximum of $933 \mathrm{~mm}$ in 1981 .

Table 1. Values of additional parameters taken to calculations (marked values used to obtain simulation for Fig. 1).

\begin{tabular}{ll}
\hline Name of parameter & Assumed values \\
\hline plough depth $d,(\mathrm{~m})$ & $0.20 ; 0.25 ; 0.30 ; 0.35$ \\
\hline soil density $B,\left(\mathrm{~kg} / \mathrm{m}^{3}\right)$ & $1100 ; 1200 ; 1300 ; 1400$ \\
\hline parameter $H,\left(\mathrm{~kg} / \mathrm{m}^{2}\right)$ & $1 ; 2 ; 4 ; 6 ; 8$ \\
\hline parameter $\gamma$ & $0.1 ; 0.2 ; 0.4 ; 0.6 ; 0.8 ; 1.0$ \\
\hline particle size correction factor $P$ & $1.0 ; 1.2 ; 1.4 ; 1.6$ \\
\hline $\begin{array}{l}\text { relative contribution of post-Chernobyl } \\
{ }^{137} \text { Cs deposition to the total }{ }^{137} \mathrm{Cs}\end{array}$ \\
\begin{tabular}{l} 
deposition, $(\%)$ \\
\hline
\end{tabular}
\end{tabular}

Generally, the highest precipitation is in July. The highest daily rainfall was recorded in July $1997-257.8 \mathrm{~mm}$. The area is contaminated by caesium from the exploded nuclear reactor in Chernobyl - about $70 \%$ of the total caesium deposition origins from the explosion in Chernobyl nuclear power plant.

The loess cover in this area has the thickness up to $10 \mathrm{~m}$. The loess sediment is homogenous with a typical grain size distribution with the mean value of $32.9 \mu \mathrm{m}$. The upper part of the loess profile does not contain carbonates.

To obtain numerical values of soil erosion, the total caesium deposition and, for some models, annual depositions must be known. The total amount of caesium deposited, i.e. the reference value, in this area is relatively simple to assess by measuring concentrations of ${ }^{137} \mathrm{Cs}$ in soil in places where neither erosion nor accumulation occur. Assessing annual depositions is more difficult, however. There are only few sites in the world where caesium deposition has been measured continuously since nuclear weapon tests started. One of possible solutions is to use the correlation between global caesium deposition and precipitation (Poręba and Bluszcz, 2007; Walling and $\mathrm{He}, 1999)$. For the purpose of this work, we use annual caesium deposition data presented in Poręba and Bluszcz (2007).

Calculations of soil erosion have been made for different values of additional parameters: $d, B, H, \gamma, P$ and for different ratios of post-Chernobyl to global caesium depositions. Ranges of values of these parameters were set on the basis of literature survey and on authors' previous research and are given in Table 1. Values of the parameter $d$ were set according to the range of ploughing depth on the loess areas. Typically, the value of plough depth for the loessial soils is between 25 and $30 \mathrm{~cm}$. The lowest and highest values of plough depth presented in Table 1 are rarely seen for specific soils or tillage. Values of soil density are typical for a loess soil. It should be mentioned that soil density may vary during the year more than uncertainty of the measurement of soil density. Moreover, soil density changes in the soil profile, but fortunately remains quite constant in the plough layer. The parameter $H$ usually varies between 2 and $6 \mathrm{~kg} / \mathrm{m}^{2}$. This value depends on the soil condition and rainfall and can be estimated experimentally by using a rainfall simulator (He and Walling, 1997). Also, establishing the value of the parameter $\gamma$ is difficult. Its value depends on the local rainfall and tillage patterns over the year (Walling and He, 1999). For areas with one ploughing and high rainfall just before the tillage, the value of this parameter is 1.0. In general, this value varies from 0.2 to 1.0 . It means that, similarly to the parameter $H$, the influence of this parameter on the final results of soil erosion calculation should be tested.

The particle size correction factor for soils ranges from 1.2 to 1.6. The value of this parameter was observed to exceed 2.0 but not for dust material. The detailed description of how to estimate $P$ were presented by $\mathrm{He}$ and Walling (1996). The particle size correction factor is defined as a ratio between specific surface area of mobilized sediment and of original soil. 
The specific surface area could be obtained from grain size distribution assuming spherical shape of particles. Compared to parameters $H$ and $\gamma$, this parameter is well defined and could be measured with high confidence.

\section{RESULTS AND DISCUSSION}

Calculations of soil erosion were performed applying the four models using the same values of model parameters. The results are presented in Fig. 1. Generally, the estimated values of soil erosion and deposition depend on the model used. The soil erosion values obtained by SMBM simplified mass balance model are higher than those obtained by RMBM. Moreover, the results of estimated soil erosion by MBM are even higher than results obtained by SMBM. The results of soil erosion obtained by the PM, RMBM and SMBM are similar, whereas the results of soil erosion estimation obtained by the MBM are substantially higher. In Fig. 2, the results of three models are presented as relative deviations from RMBM results. It may be seen again that MBM provides esti-

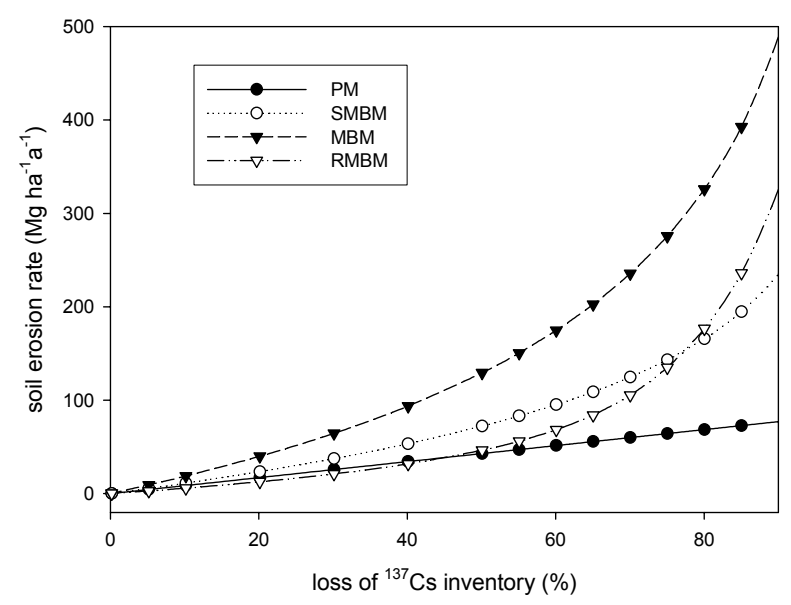

Fig. 1. Results of soil erosion calculations based on ${ }^{137} \mathrm{Cs}$ inventory data. Calculations performed for four models: PM, MBM, SMBM and RMBM (description of the models in the text).

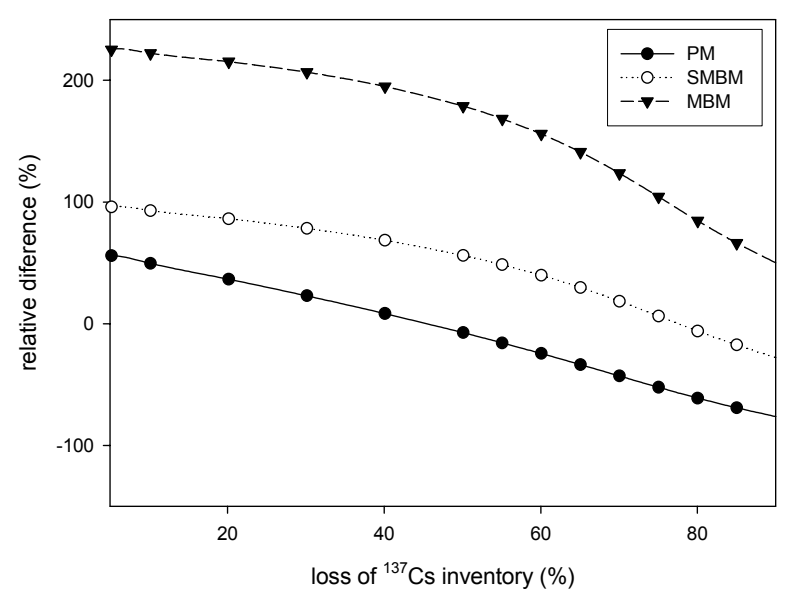

Fig. 2. Relative differences in calculated soil erosion between PM, $M B M, S M B M$ and RMBM. mates of soil erosion different from the other three models. Moreover, the difference between the RMBM and $\mathrm{PM}$ is the smallest. It is surprising, because PM is a model with the assumption, which is sometimes considered problematic. However, above $70 \%$ loss of cesium inventory the difference between $\mathrm{PM}$ and RMBM are became higher than observed for SMBM and RMBM. To recognize the sensitivity of soil erosion estimates to changes of additional parameters another calculations were performed for ranges of values of model parameters. The values of model parameters taken to calculations are presented in Table 1.

PM model uses two parameters: the plough depth $(d)$ and the soil density $(B)$. Changing the plough depth from $30 \mathrm{~cm}$ to $35 \mathrm{~cm}$ changes the calculated soil erosion by about $16.7 \%$, whereas changing the soil density of $1300 \mathrm{~kg} / \mathrm{m}^{3}$ by $100 \mathrm{~kg} / \mathrm{m}^{3}$ changes the soil erosion calculation by $7.7 \%$. In other words, the sensitivity of PM to changes of parameters $d$ and $B$ is $1 \% / \%$. This directly results from the mathematical form of this model.

Mass balance models, especially RMBM, include more parameters. The simplest case is SMBM. The simplified model does not require annual caesium deposition values; it makes an assumption that all caesium deposition took place in 1963. This assumption certainly does not hold true in the areas contaminated by the Chernobyl caesium. Nevertheless, SMBM calculations were done for the ranges of parameter values presented in Table 1. Annual soil erosion is proportional to the value of parameters $d$ and $B$, so the sensitivities are $1 \% / \%$ for both.

For MBM, calculations of the soil erosion were carried out for plough depths and soil densities given in Table 1. Results of soil erosion calculations for different plough depths are shown in Fig. 3, whereas results for different soil densities are shown in Fig. 4. It is visible, that the influence of the plough depth on the soil erosion estimation does not depend on the depletion of the ${ }^{137} \mathrm{Cs}$ from the soil profile. The sensitivities of MBM to changes of parameters $d$ and $B$ are $1 \% / \%$ for both.

In case of RMBM the influence of the parameters $P, \gamma$ and $H$ on the calculated soil erosion was studied. The influences of the plough depth and soil density on the results of soil erosion calculation are the same as in MBM.

Results of calculations of soil erosion values are presented in Figs 5-7. It is clear that the calculated soil erosion increases with the parameter $H$, while it decreases with parameters $\gamma$ and $P$. To measure the influence of these parameters on calculated erosion rates three sensitivities were defined:

$$
\begin{aligned}
& S_{P}=\left.\frac{\Delta R \%}{\Delta P \%}\right|_{P=1}, S_{\gamma}=\left.\frac{\Delta R \%}{\Delta \gamma \%}\right|_{\gamma=0.4}, \\
& S_{H}=\left.\frac{\Delta R \%}{\Delta H \%}\right|_{H=4},
\end{aligned}
$$

where:

$\Delta R \%$ is a relative change of the soil erosion rate caused by a relative change $\Delta P \%, \Delta \gamma \%$ or $\Delta H \%$ of the respective parameter. 


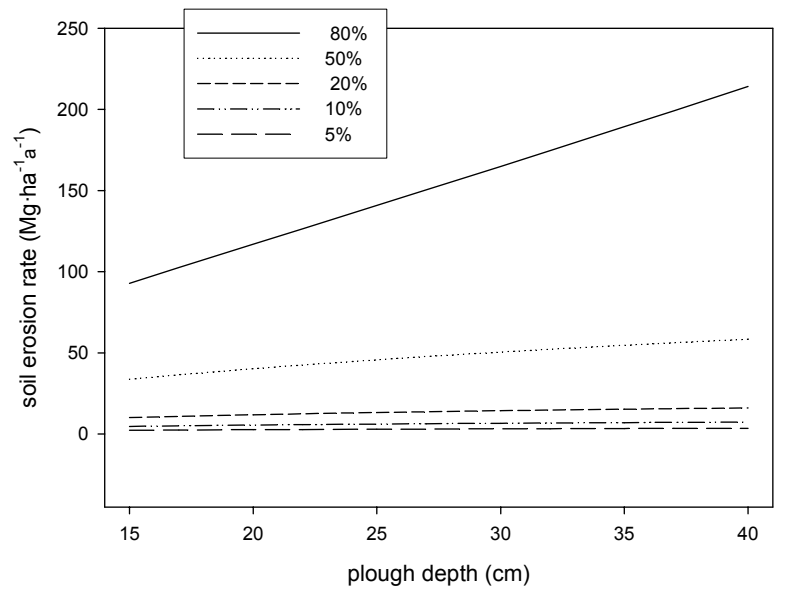

Fig. 3. The influence of the plough depth $p$ on calculated values of soil erosion in MBM. Lines plotted for different values of ${ }^{137} \mathrm{Cs}$ inventory depletion.

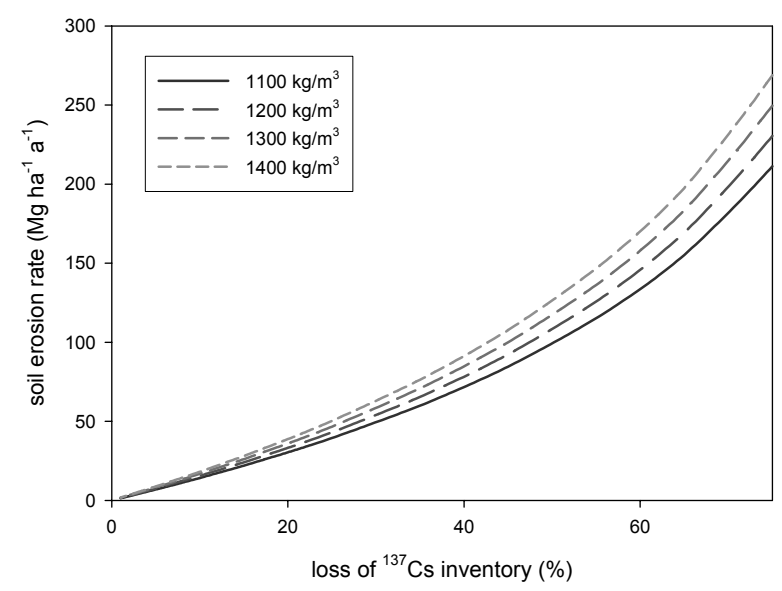

Fig. 4. The influence of soil density $B$ on calculated values of soil erosion in MBM. Lines plotted for four different values of soil density.

The sensitivities were calculated for three different ${ }^{137} \mathrm{Cs}$ depletions and are presented in Table 2. It occurs that RMRM is more sensitive to the parameter $P$ than to parameters $H$ or $\gamma$. Fortunately, the value of the parameter $P$ may be established with a good accuracy by measuring grain size distributions for soil and for transported sediment. The values of parameters $\gamma$ and $H$ are difficult to establish with good accuracy (Walling and He, 1999).

The accident in Chernobyl nuclear power plant in 1986 presents another problem for the soil erosion determination by a ${ }^{137} \mathrm{Cs}$ method because a large part of Europe was contaminated by the caesium released during this event. In case of SMBM or PM, this additional deposition can not be accounted for and makes the calculation of soil erosion rates incorrect. MBM and RMBM require annual values of ${ }^{137} \mathrm{Cs}$ deposition and correct values of postChernobyl caesium fallout are essential for them. In the short period directly after the Chernobyl accident, it was possible to calculate the share of the Chernobyl caesium in the total caesium by measuring another caesium isotope $-{ }^{134} \mathrm{Cs}$. This isotope has a short half-life time (about

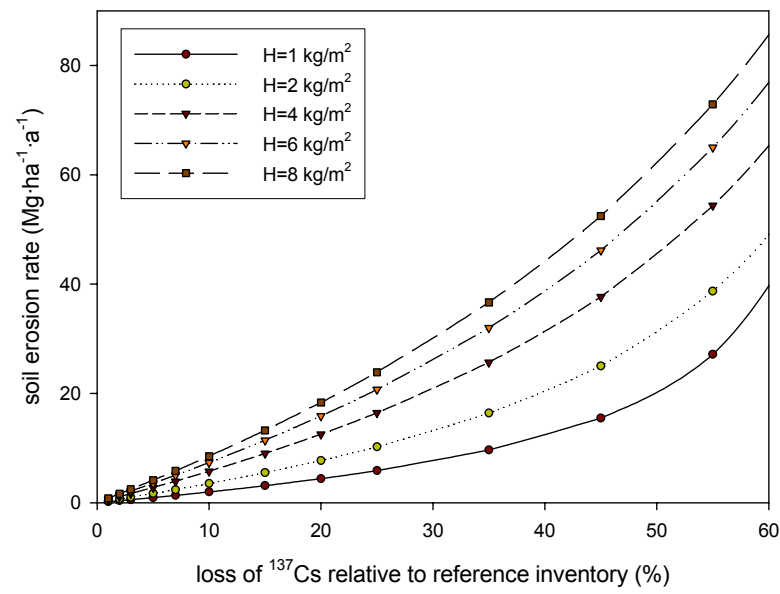

Fig. 5. The influence of parameter $H$ on calculated values of soil erosion in RMBM. Lines plotted for five different values of the parameter.

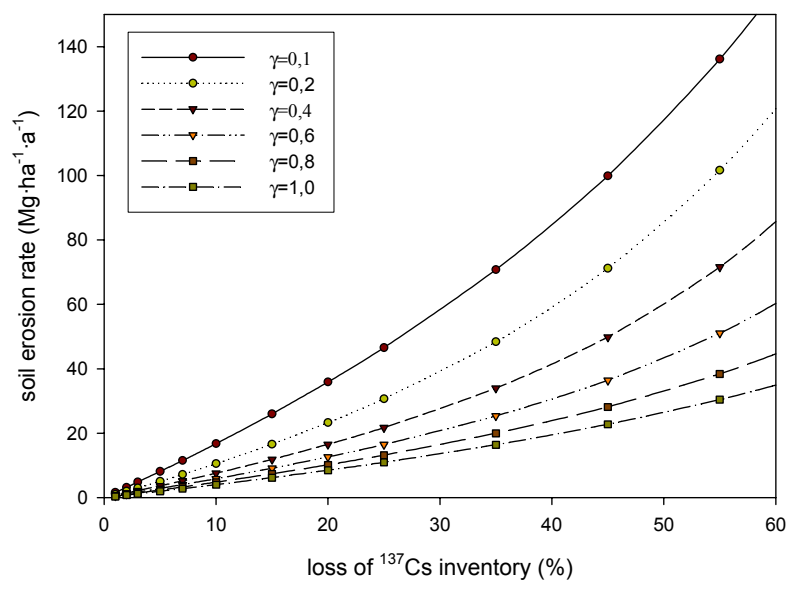

Fig. 6. The influence of parameter $y$ on calculated values of soil erosion in RMBM. Lines plotted for different values of the parameter.

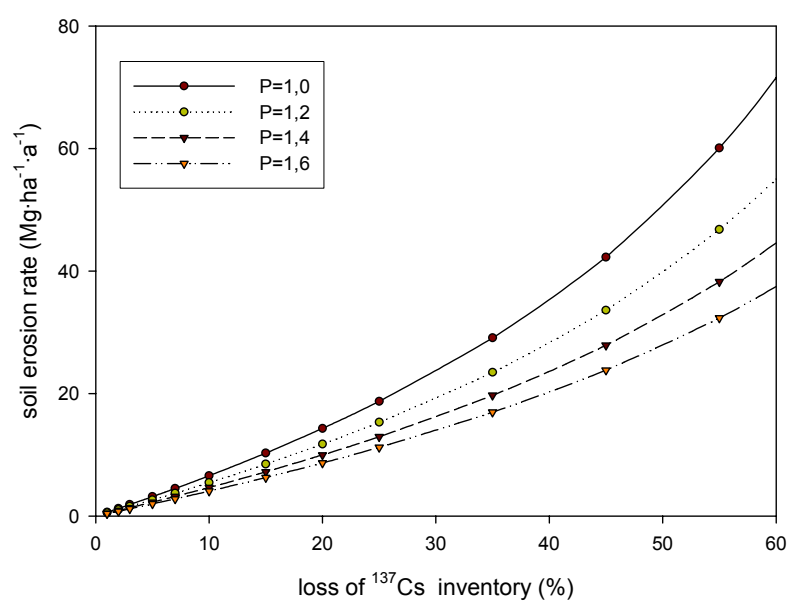

Fig. 7. The influence of the parameter $P$ on calculated values of soil erosion in RMBM. Lines plotted for four different values of the parameter. 
2 years) and had been once used as a tracer of the postChernobyl deposition. But now, about 20 years later, this possibility is no longer available. Another solution of this problem is to use the local rainfall record and its correlation with the global Cs fallout (Poręba and Bluszcz, 2007). This procedure introduces additional uncertainties and to estimate their importance additional calculations were performed. Results of calculations for varying postChernobyl caesium contributions are presented in Fig. 8. They show that soil erosion rates calculated in RMBM depend on $C h$ parameter defined as:

$C h=\frac{A_{C h}}{A_{t o t}} 100$

where:

$A_{C h}$ and $A_{t o t}$ are post-Chernobyl and total ${ }^{137} \mathrm{Cs}$ inventories respectively.

The relationship between the soil erosion rate and the contribution of post-Chernobyl caesium is non-linear. To illustrate the fact a sensitivity $S_{C H}$ was defined:

$S_{C h}=\left.\frac{\Delta R \%}{\Delta C h \%}\right|_{C h=60}$

where:

$\Delta C h \%$ - is a relative change of the relative contribution of post-Chernobyl caesium in the total caesium deposi-

Table 2. The obtained values of sensitivities of the RMBM to the parameters $P, \gamma$ and $H$.

\begin{tabular}{lccc}
\hline & \multicolumn{3}{c}{ The loss of ${ }^{137}$ Cs inventory $(\mathrm{X}),(\%)$} \\
& $\mathbf{2 0}$ & $\mathbf{4 0}$ & $\mathbf{6 0}$ \\
Parameter & \multicolumn{3}{c}{ Sensitivity } \\
\hline$H$ & 0.56 & 0.50 & 0.37 \\
$Y$ & -0.71 & -0.74 & -0.77 \\
$P$ & -0.88 & -0.95 & -1.14 \\
Ch & 0.14 & 0.16 & 0.19 \\
\hline
\end{tabular}

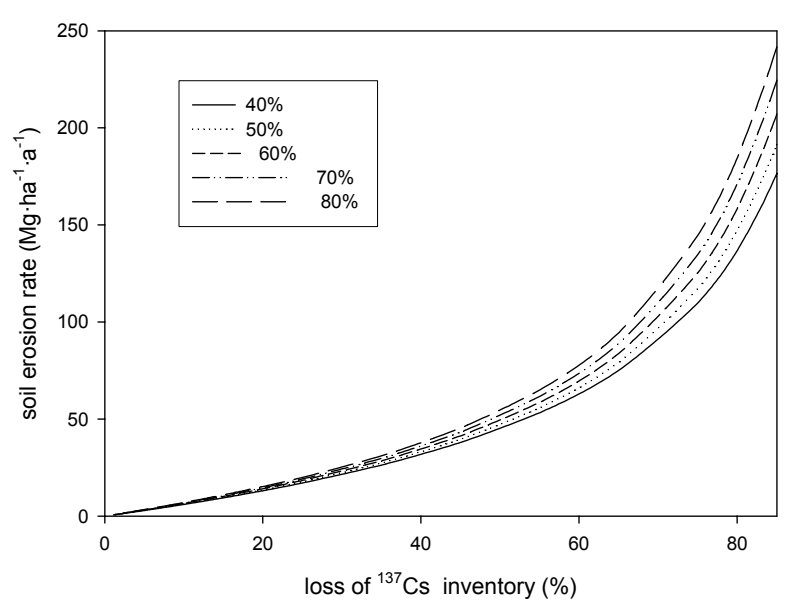

Fig. 8. The influence of post-Chernobyl ${ }^{137} \mathrm{Cs}$ deposition on calculated values of soil erosion in RMBM. Lines plotted for five different values of the contribution of post-Chernobyl deposition to the total ${ }^{137} \mathrm{Cs}$ deposition. tion and calculated for different $X$ values. The calculated sensitivities are given in Table $\mathbf{2}$ and they show that RMBM is quite resistant to possible errors in estimating post-Chernobyl deposition of ${ }^{137} \mathrm{Cs}$.

\section{CONCLUSIONS}

We have shown how the calculated values of soil erosion rates depend on the model and on the values of its parameters for given experimental data. Among the four analyzed models, MBM yields results that are significantly larger than results of RMBM, SMBM and PM. However, for data without post-Chernobyl caesium contribution MBM and SMBM yield closer results - the difference is around $10 \%$ only.

PM produces results that are significantly higher than RMBM results for $X$ below $40 \%$ and lower than RMBM results for $X$ above $70 \%$. SMBM basically could not be used for a studied area produces much higher figures of erosion rates than RMBM does. For $X$ below 40\%, SMBM erosion rates are about twice as big as RMBM ones.

The influence of errors in model parameters on results of soil erosion rate estimates is acceptable (about $1 \%$, or less, for $1 \%$ relative error) and is comparable with uncertainties of measurements.

\section{REFERENCES}

He Q and Walling DE, 1997. The distribution of fallout ${ }^{137} \mathrm{Cs}$ and ${ }^{210} \mathrm{~Pb}$ in undisturbed and cultivated soils. Applied Radiation and Isotopes 48(5): 677-690, DOI 10.1016/S0969-8043(96)00302-8.

de Jong E, Begg CBM and Kachanowski RG, 1983. Estimates of soil erosion and deposition for some Saskatchewan soils. Canadian Journal of Soil Science 63: 607-617.

Kachanowski RG, 1987. Comparison of measured soil 137-caesium losses and erosion rates. Canadian Journal of Soil Science 67: 199-203.

Kachanowski RG and de Yong E, 1984. Predicting the temporal relationship between soil caesium-137 and erosion rate. Journal of Environmental Quality 13: 301-304.

Menzel R, 1960. Transport of strontium-90 in runoff. Science 131: 499500, DOI 10.1126/science.131.3399.499.

Poręba G, 2006. Zastosowanie ${ }^{137} \mathrm{Cs}$ do modelowania procesów erozji i akumulacji na obszarach lessowych (Using of ${ }^{137} \mathrm{Cs}$ to study soil erosion and accumulation processes on the loess areas). PhD thesis, Gliwice, Silesian University of Technology: 165 pp (in Polish).

Poręba G. and Bluszcz A, 2007. Determination of the initial ${ }^{137} \mathrm{Cs}$ fallout on the areas contaminated by Chernobyl fallout. Geochronometria 26 : 34-38.

Ritchie JC and McHenry JR, 1975. Fallout Cs-137: a tool in conservation research. Journal of Soil and Water Conservation 30: 283286.

Ritchie JC and McHenry JR, 1990. Application of radioactive fallout caesium-137 for measuring soil erosion and sediment accumulation rates and patterns: a review. Journal of Environmental Quality 19: 215-233.

Ritchie JC, Spraberry JA and McHenry JR, 1974. Estimating soil erosion from the redistribution of fallout ${ }^{137} \mathrm{Cs}$. Soil Science society of America Proceedings 38: 137-139.

Rogowski AS and Tamura T, 1965. Movement of ${ }^{137} \mathrm{Cs}$ by runoff, erosion and infiltration on the alluvial captina silt loam. Health Physics 11(12): 1333-1340, DOI 10.1097/00004032-19651200000010.

Rogowski AS and Tamura T, 1970. Environmental mobility of caesium137. Radiation Botany 10(1): 35-45, DOI 10.1016/S00337560(70)80050-3. 
Sawhney BL, 1972. Selective sorption and fixation of cations by clay minerals: a review. Clays and Clay Minerals 20: 93-100, DOI 10.1346/CCMN.1972.0200208.

Schulz RK, 1965. Soil chemistry of radionuclides. Health Physics 11(12): 1317-1324, DOI 10.1097/00004032-196512000-00008.

Schulz RK, Overstreet R and Barshad I, 1960. On the soil chemistry of caesium 137. Soil Science 89(1): 16-27, DOI 10.1097/00010694196001000-00004.

Tamura T, 1964. Selective sorption reaction of caesium with mineral soils. Nuclear Safety 5: 262-268.

Toy TJ, Foster GR and Renard KG, 2002. Soil erosion: processes, prediction, measurement, and control. New York, John Wiley \& Sons: $338 \mathrm{pp}$.

Walling DE and He Q, 1999. Improved models for estimating soil erosion rates from caesium-137 measurements. Journal of Environmental Quality 28(2): 611-622.
Walling DE and Quine TA, 1990. Calibration of caesium-137 measurements to provide quantitative erosion rate data. Land Degradation and Rehabilitation 2(3): 161-175, DOI 10.1002/ldr.3400020302.

Yamagata N, Matsuda S and Kodaira K, 1963. Run-off of caesium-137 and strontium-90 from rivers. Nature 200: 668-669, DOI $10.1038 / 200668 \mathrm{~b} 0$.

Zapata F, 2003. The use of environmental radionuclides as tracers in soil erosion and sediment investigations: recent advantages and future developments. Soil and Tillage Research 69: 3-13, DOI 10.1016/S0167-1987(02)00124-1.

Zhang XB, Higgitt DI and Walling DE, 1990. A preliminary assessment of the potential for using caesium-137 to estimate rates of soil erosion in the Loess Plateau of China. Hydrological Sciences 35: 243 252. 